\title{
Anesthetic substance abuse: international perspectives and parallels
}

\author{
Lewis Ellerton Fry $\cdot$ Robert Andrew Fry, MBChB
}

Received: 20 July 2015/Revised: 3 August 2015/Accepted: 8 September 2015/Published online: 16 September 2015

(c) Canadian Anesthesiologists' Society 2015

\section{To the Editor}

We read with interest the article by Boulis et al. that once again highlights the persistent problem of substance abuse in anesthesia. ${ }^{1}$ This study adds to an international body of literature that poses more questions than answers and indicates that the profession has still not found adequate solutions to this challenge. The lack of accurate data is also a significant barrier to unravelling this complex issue. In Australasia, the Welfare of Anaesthetists, a special interest group of the Australian and New Zealand College of Anaesthetists (ANZCA), has devoted over 20 years advocating unsuccessfully for an anonymous reporting scheme. As a result, we have also had to rely on similar surveys over each of the past three decades-the most recent published this year ${ }^{2}$ - and commend Boulis et al. for their contribution.

The results of our recent analysis of 30 years of substance use disorder (SUD) in residents is comparable with both the Canadian data and the findings of Berge et al. in the United States., ${ }^{3,4}$ The most divergent result in Australasia, however, has been the high incidence of propofol abuse, particularly over the last decade. In the

Editor's Note: The authors of the article: Can J Anesth 2015; DOI: $10.1007 / \mathrm{s} 12630-015-040-1$, respectfully declined an invitation to submit a reply to the above letter.

\section{E. Fry ( $ه)$}

Monash Medical School, Monash University, Melbourne, VIC, Australia

e-mail: lewis.fry@gmail.com

R. A. Fry, MBChB

Department of Anaesthesia, Auckland City Hospital, Auckland, New Zealand most recent ten-year survey of Australasian anaesthetists, 61 cases were reported, an incidence of 1.2 cases per 1,000 anaesthetist years. Propofol was involved in 18 of the 44 $(41 \%)$ cases reported in adequate detail for analysis. Death was the eventual outcome in eight of these 18 cases involving propofol, a particularly high mortality rate of $44 \%$. Propofol abuse was particularly common amongst the residents in our dataset, reported in ten of $18(56 \%)$ cases. Unfortunately, the rate of successful return to work by Australasian anaesthetists with reported SUD has consistently fallen below that achieved in North American studies; only 14 of $44(32 \%)$ anaesthetists remained in anaesthesia in the last survey. ${ }^{2}$ This is likely partly due to a lack of physician health programs in Australasia, a recognized shortage of addiction specialists, and inconsistencies in treatment protocols.

In response to this, ANZCA, in conjunction with the Royal Australian and New Zealand College of Psychiatrists, has recently convened a working group of physicians with an interest in the area to establish some consistent treatment guidelines. While prevention should be the ultimate goal, as noted by Berge "Addicts are smart, we're smart; they're desperate, we're not desperate so they're going to outsmart us every time". ${ }^{5}$ No amount of restriction, workplace drug testing, automated dispensing machines, or education will entirely prevent this affliction which is unfortunately far too common in anesthesia.

Conflicts of interest None declared.

\section{References}

1. Boulis $S$, Khanduja K, Downey K, Friedman Z. Substance abuse: a national survey of Canadian residency program directors and site 
chiefs at university-affiliated anesthesia departments. Can J Anesth 2015; DOI:10.1007/s12630-015-040-1.

2. Fry RA, Fry LE, Castanelli DJ. A retrospective survey of substance abuse in anaesthetists in Australia and New Zealand from 2004 to 2013. Anaesth Intensive Care 2015; 43: 111-7.

3. Fry RA, Fry LE, Weeks A. Substance use disorder amongst Australian and New Zealand anaesthetic trainees: an analysis of 30 years of data. Anaesth Intensive Care 2015; 43: 530.
4. Warner DO, Berge K, Sun H, Harman A, Hanson A, Schroeder $D R$. Substance use disorder among anesthesiology residents, 19752009. JAMA 2013; 310: 2289-96.

5. Stemwedel, JD. Anesthesiology and Addiction. Adventures in Ethics and Science - 2009 Available from URL: http://scienceblogs.com/ ethicsandscience/2009/01/08/anesthesiology-and-addiction/ (accessed August 2015) 